\title{
Finnegan Score Measurement
}

National Cancer Institute

\section{Source}

National Cancer Institute. Finnegan Score Measurement. NCI Thesaurus. Code C89343.

A tool to evaluate neonatal abstinence syndrome (NAS), that measures the degree to which a neonate is experiencing symptoms of withdrawal due to maternal substance abuse. 